Check for updates

Cite this: Soft Matter, 2018, 14,8846

Received 6th July 2018, Accepted 12th August 2018

DOI: $10.1039 / c 8 s m 01389 f$

rsc.li/soft-matter-journal

\title{
A novel nematic-like mesophase induced in dimers, trimers and tetramers doped with a high helical twisting power additive $\uparrow$
}

\author{
Richard J. Mandle (D) * and John W. Goodby \\ From the observation of a previously undiscovered nematic-like mesophase $\left(\mathrm{N}_{\mathrm{X}}\right)$ by Archbold et al., we \\ report on several new binary liquid-crystalline mixtures between the high helical twisting power dopant \\ RM1041 and a selection of dimers with varying average bend angles and conformational landscapes. We \\ also report on mixtures between RM1041 and oligomeric LC materials. We find that dimers and \\ oligomers exhibit not only chiral nematic and twist-bend modulated phases, but also the same $N_{X}$ phase \\ reported by Archbold, indicating that this state of matter (the structure of which is yet to be definitively \\ characterised) is exhibited by a wide range of materials. Mixtures of the dimer CB9CB with a selection of \\ different chiral dopants suggest that it is the helical twisting power of the chiral additive that is \\ responsible incidence of the $\mathrm{N}_{\mathrm{X}}$ phase.
}

\section{Introduction}

The discovery of the twist-bend modulated (TB) phase has led to resurgence in the interest in liquid-crystalline dimers and bimesogens. ${ }^{1,2}$ The TB phase possesses a helical structure with a pitch length of a few nanometers. ${ }^{3-5}$ The TB phase is therefore chiral despite being typically formed by achiral molecules, whereas conversely only a handful of chiral materials are known to exhibit this phase. $^{6,7}$ The TB phase exhibits striking optical textures ${ }^{8}$ and has been studied by resonant ${ }^{3,9}$ and non-resonant SAXS, ${ }^{10} \mathrm{NMR}^{11-13}$ polarised Raman spectroscopy, ${ }^{14}$ and under applied electric ${ }^{15}$ and magnetic fields. ${ }^{16}$ This phase is principally exhibited by liquidcrystalline dimers, ${ }^{17}$ in which two rigid sections are adjoined by a (semi) flexible spacer. Experimental results suggest it is primarily molecular shape $\mathrm{e}^{18-20}$ and the gross bend-angle that appear to dictate the incidence of this phase,$^{20-22}$ supporting the findings of earlier theoretical treatments. ${ }^{23,24}$ In addition to being found in achiral materials, a number of chiral dimers/bimesogens are known to exhibit the TB phase. ${ }^{6,7,25}$ In addition to low molecular weight dimers the TB phase is also found in oligomers, ${ }^{26-29}$ polymers $^{30,31}$ and possibly lyotropic systems. ${ }^{32}$ Several examples of transitions from the TB phase into smectic phases are known, such as smectic ${ }^{33-37}$ and $\mathrm{B}_{6}$ phases. ${ }^{38,39}$

Recently, Archbold et al. reported that the binary mixture M10 forms a novel nematic liquid-crystalline state upon cooling

Chemistry, University of York, York, UK. E-mail: richard.mandle@york.ac.uk, john.goodby@york.ac.uk

$\dagger$ Electronic supplementary information (ESI) available. See DOI: 10.1039/ c8sm01389f from the TB phase, this being the only example of a transition from the TB phase into a lower temperature (presumably modulated) nematic-like phase. This previously undiscovered nematic modification, termed $\mathrm{N}_{\mathrm{X}}$, is observed when the host material 'CA23' (Fig. 1) is doped with the high helical twisting power (HTP) dopant 'RM1041' (Fig. 1). ${ }^{40}$ The $\mathrm{N}_{\mathrm{X}}$ phase was found to exhibit only diffuse scattering of X-rays at small- and wide-angles, and to retain many of the optical textures of the preceding TB phase. Although the structure of the lower temperature phase has not been identified, the lack of Bragg scattering in SAXS/WAXS experiments confirms its nematic-like nature. High weight percent mixtures of RM1041 in CA23 also exhibit direct isotropic-to-TB phase transitions, such as M10

\section{a.}

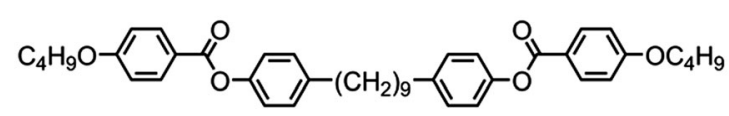

b.

Cr 83.3 TB 84.7 N 99.5 Iso

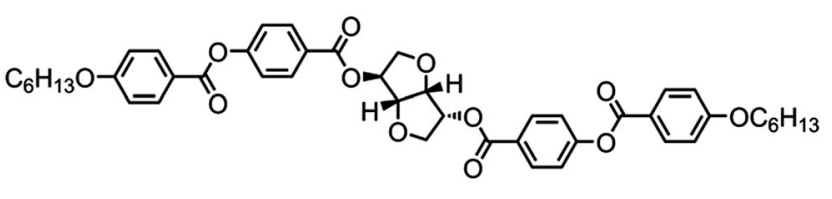

Cr 141.7 (SmA 137.6) Iso

$$
\begin{gathered}
\operatorname{M10}(90 \% \text { a, } 10 \% \text { b) } \\
\text { Cr } 79.1 \mathrm{~N}_{\mathrm{X}} 69.6 \mathrm{~TB} 79.2 \text { Iso }
\end{gathered}
$$

Fig. 1 Molecular structures and transition temperatures $\left({ }^{\circ} \mathrm{C}\right)$ of CA23 (a) and RM1041 (b). The composition and transition temperatures of the mixture 'M10' are indicated. 
shown in Fig. 1. In this report we revisit this topic, preparing mixtures of several dimers (CBCC6OCB, CB9CB, CB8OCB), trimers $\left(\mathrm{A}_{3}\right.$ and $\left.\mathrm{T} 3_{9}\right)$ and tetramers $\left(\mathrm{T}_{9}, \mathrm{O}_{7}\right)$ with the same chiral dopant used by Archbold (RM1041), with a view to discovering new examples of the $\mathrm{N}_{\mathrm{X}}$ mesophase, and examining the universal nature of the $\mathrm{N}_{\mathrm{X}}$ phase.

\section{Experimental}

Binary mixtures were prepared by weighing each component separately, dissolving each into dichloromethane before combining the two solutions and mixing with sonication ( $>5 \mathrm{~min}$ ). The dichloromethane was removed by warming the sample under a stream of dry nitrogen gas for $24 \mathrm{~h}$. Unless otherwise stated, mixtures contain $90 \mathrm{wt} \%$ of the host material, and $10 \%$ of the chiral dopant RM1041. The syntheses of all materials used in this study were described previously (RM1041; ${ }^{40}$ CB9CB, CBCC6OCB and $\mathrm{CB} 8 \mathrm{OCB} ;{ }^{41} \mathrm{~T}_{3} 9 ;{ }^{42} \mathrm{~T}_{4} 9 ;{ }^{42,43} \mathrm{A6}_{3} ;{ }^{27} \mathrm{O}_{7}{ }^{44}$ ) and their molecular structures and transition temperatures are given in the $\mathrm{ESI} \dagger$ to this article. Transition temperatures of neat materials and their molecular structures are given in the $\mathrm{ESI} \dagger$ to this article. Computational chemistry was performed in Gaussian G09 revision E01. ${ }^{45}$ Output files were rendered in Qutemol. ${ }^{46}$ Conformational analysis was performed as described by Archbold et al., ${ }^{22}$ with the AM1 semi-empirical method used to generate conformer libraries. Details of instrumentation employed in this study are given in the $\mathrm{ESI} \uparrow$ to this article.

\section{Results}

We first studied binary mixtures (90 wt\% host, $10 \mathrm{wt} \%$ RM1041) between the dimers CBCC6OCB, CB9CB and CB8OCB and the chiral dopant RM1041. Transition temperatures were determined by polarised optical microscopy (POM) and differential scanning calorimetry (DSC), whereas phase assignments were made by POM, and small- and wide-angle X-ray scattering (SAXS/WAXS). Enthalpies are presented in $\mathrm{kJ} \mathrm{mol}^{-1}$ using a weight average of the molecular weight of each component. Transition temperatures and associated enthalpies are presented in Table 1 alongside data for M10, which is provided as a comparison. $^{40}$

All three mixtures exhibit chiral nematic $\left(\mathrm{N}^{*}\right)$ and twist-bend nematic (TB) phases, which were identified based on their optical textures (Fig. 2) and X-ray scattering patterns (see Fig. 3). In all samples we found further cooling of the TB phase yielded a phase transition into what we term the ' $N_{X}$ ' phase, a nematic-like phase of unknown structure. At the transition into the $\mathrm{N}_{\mathrm{X}}$ phase there is a marked change in birefringence (Fig. $2 \mathrm{~b}$ and $\mathrm{c}$ ), however the principal optical textures of the preceding TB phase (parabolic, focal conic, rope-texture) are retained following the phase transition. All three phases are fluid and visibly flow during POM study, although the $\mathrm{N}^{*}$ phase is notably more fluid than both the $\mathrm{TB}$ or $\mathrm{N}_{\mathrm{X}}$ phases. Shearing the $\mathrm{TB}$ or $\mathrm{N}_{\mathrm{X}}$ phase leads to a pseudo homeotropic texture which can be restored to the birefringent texture either via thermal
Table 1 Transition temperatures $\left(T,{ }^{\circ} \mathrm{C}\right)$ associated enthalpies $\left(\Delta H, \mathrm{~kJ} \mathrm{~mol}^{-1}\right)$ for binary mixtures $\mathbf{1}$ Mix, 2Mix and 3Mix, featuring the host (90 wt\%) and RM1041 (10 wt\%). Transition temperatures and associated enthalpies were determined by DSC at $10{ }^{\circ} \mathrm{C} \mathrm{min}-1$ and are the average of two cycles. The scaled TB transition temperatures $\left(T_{\mathrm{TB}-\mathrm{N}} / T_{\mathrm{N}-\text { Iso }}\right)$ are $0.95,0.90$ and 0.89 for $\mathbf{1}$ Mix, 2Mix and 3 Mix respectively. The scaled $\mathrm{N}_{\mathrm{X}}$ transition temperatures $\left(T_{\mathrm{X}-\mathrm{TB}} / T_{\mathrm{N}-\mathrm{Iso}}\right)$ are $0.90,0.86$ and 0.84 for $\mathbf{1}$ Mix, 2 Mix and 3 Mix respectively

\begin{tabular}{|c|c|c|c|c|c|c|}
\hline Mix. no. & Host & & MP & $\mathrm{N}_{\mathrm{X}}-\mathrm{TB}$ & TB- $\mathrm{N}^{*}$ & $\mathrm{~N}^{*}$-Iso \\
\hline M10 & CA23 & $\begin{array}{l}T \\
\Delta H\end{array}$ & $\begin{array}{c}79.1 \\
-b\end{array}$ & $\begin{array}{c}69.6 \\
-b\end{array}$ & $\begin{array}{l}79.2^{a} \\
-b\end{array}$ & - \\
\hline \multirow[t]{2}{*}{ 1Mix } & 1 & $T$ & 85.9 & 81.3 & 98.2 & 116.9 \\
\hline & СB9CB & $\Delta H$ & 33.4 & 0.2 & 0.7 & 1.7 \\
\hline \multirow[t]{2}{*}{$2 \mathrm{Mix}$} & 2 & $T$ & 107.6 & 91.1 & 106.2 & 148.1 \\
\hline & CB8OCB & $\Delta H$ & 38.4 & $<0.1$ & $<0.1$ & 1.9 \\
\hline \multirow[t]{2}{*}{ 3Mix } & 3 & $T$ & 132.6 & 76.7 & 94.8 & 144.5 \\
\hline & СВСС6ОСB & $\Delta H$ & 27.9 & 0.3 & $<0.1$ & 1.2 \\
\hline
\end{tabular}

${ }^{a}$ Direct $\mathrm{N}_{\mathrm{TB}}$ to Iso transition. ${ }^{b}$ Enthalpy values not reported in ref. 40.
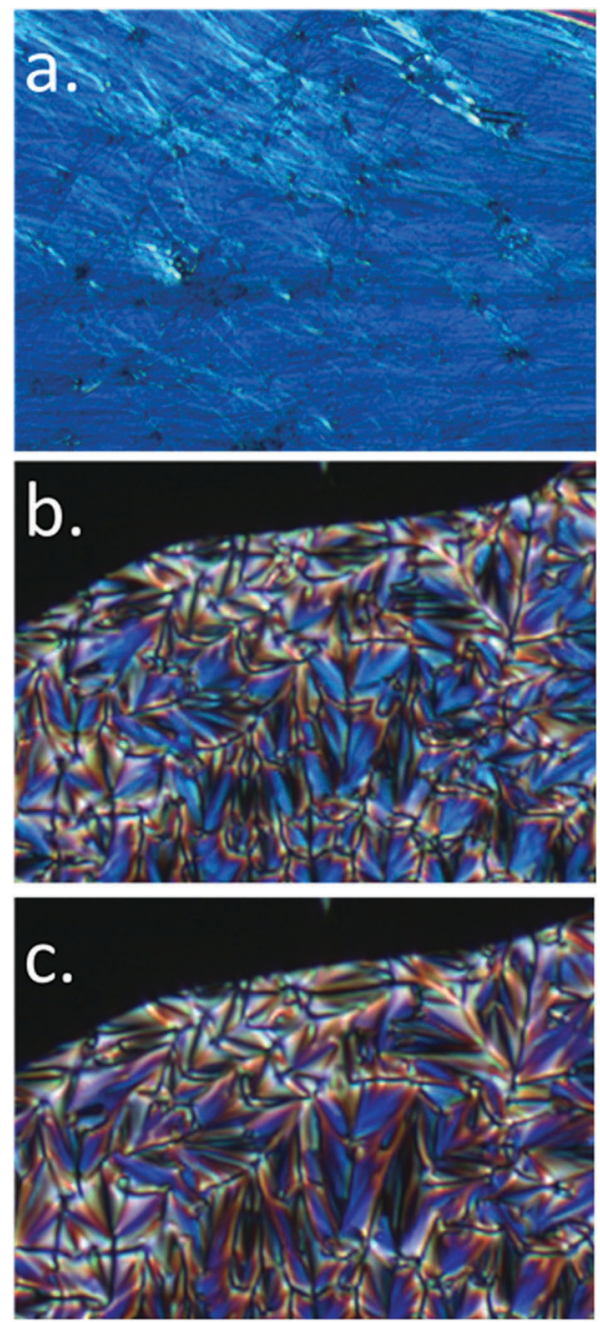

Fig. 2 Photomicrographs $(\times 100)$ of (a) the $\mathrm{N}^{*}$ phase of $\mathbf{1 M i x}$ at $111.4{ }^{\circ} \mathrm{C}$, (b) TB texture of $\mathbf{2}$ Mix at $102.1^{\circ} \mathrm{C}$, (c) the texture of the $\mathrm{N}_{x}$ phase of $\mathbf{2}$ Mix at $74.5^{\circ} \mathrm{C}$. Note that (b) and (c) depict approximately the same region of the slide.

annealing or heating into the $\mathrm{N}^{*}$ phase and cooling back to the TB or $\mathrm{N}_{\mathrm{X}}$. Further examples for mixtures in this paper are given in the ESI. $\dagger$ 

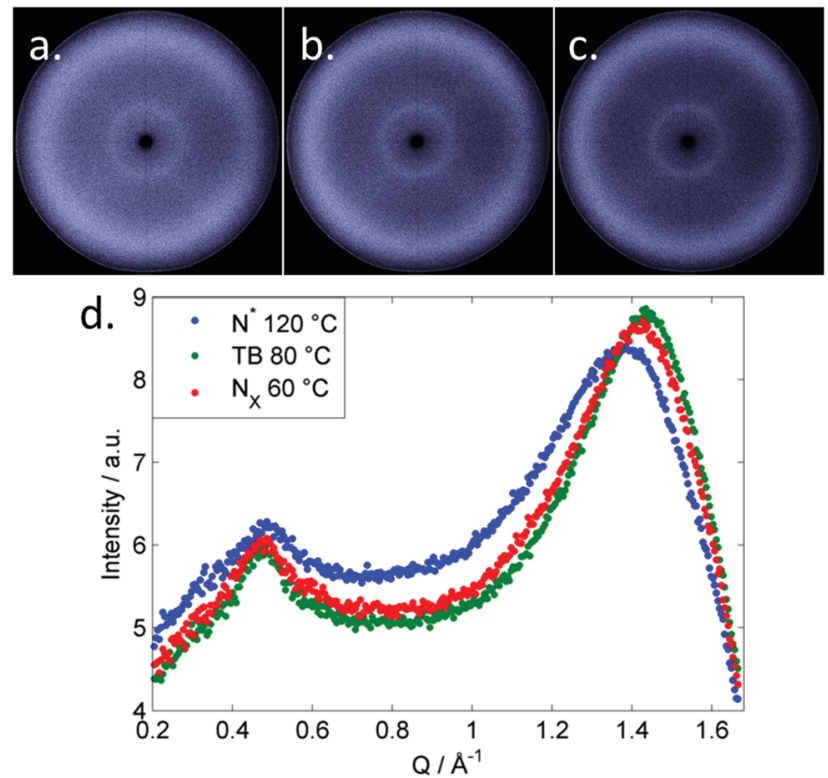

Fig. 3 SAXS studies on 3Mix: (a) 2D SAXS pattern of the $N^{*}$ phase at $120^{\circ} \mathrm{C}$; (b) $2 \mathrm{D}$ SAXS pattern of the TB phase at $80^{\circ} \mathrm{C}$; (c) $2 \mathrm{D}$ SAXS pattern of the $\mathrm{N}_{\mathrm{X}}$ phase at $60^{\circ} \mathrm{C}$; (d) plot of intensity (arb) vs. the scattering vector $Q$ $\left(\AA^{-1}\right)$ for $\mathbf{3}$ Mix at the three temperatures indicated.

We studied 3Mix by small angle X-ray scattering as a function of temperature. As with many LC dimes we observed extremely weak small angle scattering in all phases (with the exception of the solid state), we attribute this to a near absence of cybotactic fluctuations in the nematic and TB phases. The chiral nematic and TB phases give typical nematic-like scattering patterns, with only diffuse scattering at wide- and small-angles (Fig. 3). The lack of Bragg or quasi-Bragg scattering at small angles demonstrates the $\mathrm{N}_{\mathrm{X}}$ phase is not a lamellar phase. On cooling from the TB phase into the $\mathrm{N}_{\mathrm{X}}$ phase the 2D SAXS patterns (Fig. $3 \mathrm{~b}$ and c) appear indistinguishable, however as shown in Fig. $3 \mathrm{~d}$ there is a very slight increase in the intensity of the wide-angle scattering peak and a slight decrease in $d$-spacing, however the small angle peak appears to remain unchanged. Aside from the diffuse peak at $\sim 13 \AA$ there are no further peaks in the small-angle region up to the maximum $Q$ range we can study $\left(\approx 0.05 \AA^{-1}\right)$. As discussed by Zhu et al., the hypothetical splay-bend nematic phase lacks the glide symmetry present in the TB phase and this should therefore lead to Bragg scattering of hard X-rays. ${ }^{3}$ We therefore tentatively exclude a splay-bend phase whose modulation period is smaller than $Q=0.05 \AA^{-1}(\sim 120 \AA)$, however it has also been argued that the periodicity of a splay-bend nematic can only be revealed by resonant X-ray scattering experiments. ${ }^{47}$

Just as the TB phase exhibits a dependency upon the gross molecular bend and flexibility, we suspect the $\mathrm{N}_{\mathrm{X}}$ phase will also exhibit a similar dependency. We therefore studied the conformational landscape of $\mathrm{CBCC6OCB}$ with the AM1 semi empirical method. Data for CB8OCB and CB9CB was presented by us in ref. 19. As expected, the probability of a given bend-angle for CBCC6OCB is largely the same as CB8OCB, with the caveat that the reduced flexibility of the spacer leads to a reduction in the population of hairpin and linear forms. The distribution of

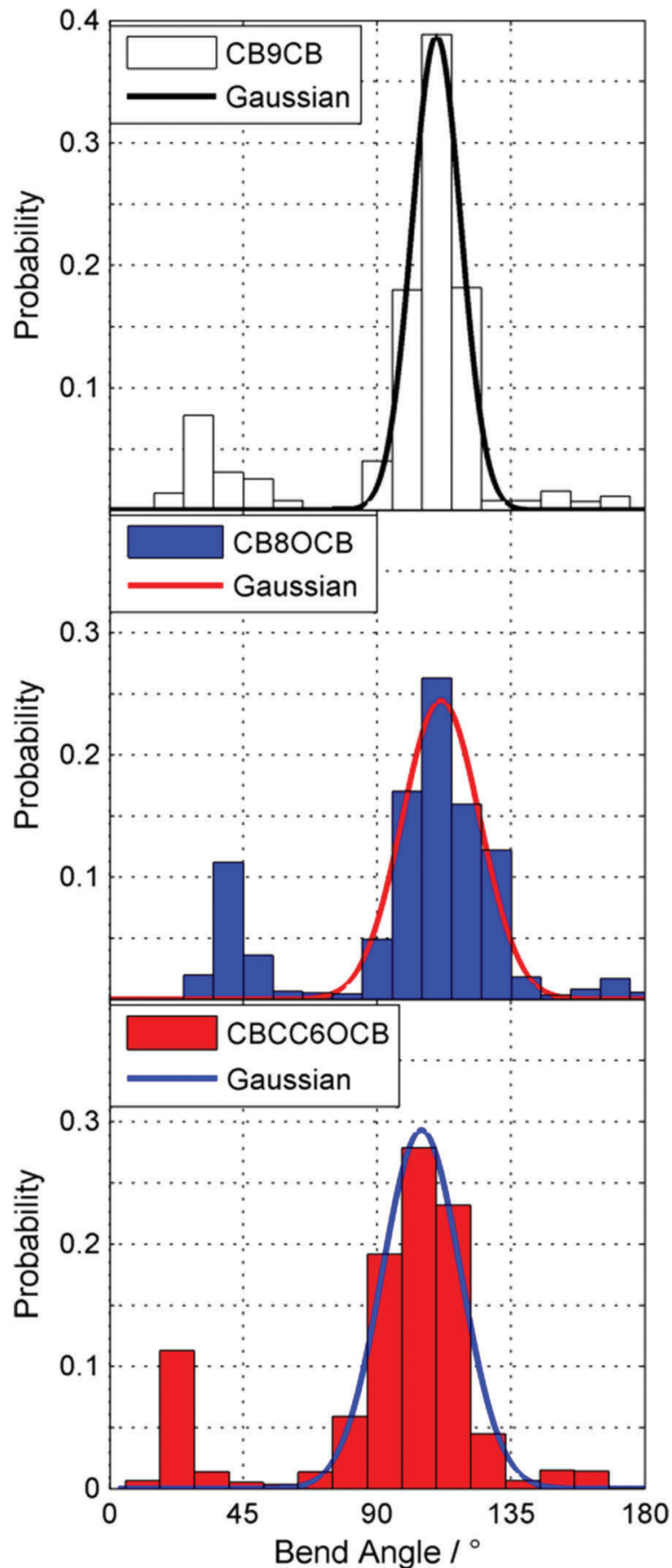

Fig. 4 Histogram plots of bend angle probability shown as a function of the bend-angle for $\mathrm{CB} 9 \mathrm{CB}, \mathrm{CB} 8 \mathrm{OCB}$ and $\mathrm{CBCC6OCB}$ along with a Gaussian fit centered at $102^{\circ}$ (FWHM of $18^{\circ}$ ), $104^{\circ}$ (FWHM of $31^{\circ}$ ) and $105^{\circ}$ (FWHM of $39^{\circ}$ ) respectively.

bend angles centered around $105^{\circ}$ for each material is approximately Gaussian (Fig. 4). We fit each histogram plot with a Gaussian function, the FWHM of which we take as a measure of the distribution of bend angles (Fig. 4). As the FWHM will display a dependency on the bin size in each histogram, the values we present herein are an average value of the FWHM for a range of bin sizes $\left(1-60^{\circ}\right.$ in $0.33^{\circ}$ steps). A plot of FWHM versus 
Table 2 Transition temperatures $\left(T,{ }^{\circ} \mathrm{C}\right)$ associated enthalpies $\left(\Delta H, \mathrm{~kJ} \mathrm{~mol}^{-1}\right)$ for binary mixtures $\mathbf{4 M i x}-\mathbf{7 M i x}$, featuring the indicated host (90 wt\%) and RM1041 (10 wt\%). Transition temperatures and associated enthalpies were determined by DSC at $10{ }^{\circ} \mathrm{C} \mathrm{min}-1$ and are the average of two cycles

\begin{tabular}{lllrrrr}
\hline Mix. no. & Host & & \multicolumn{1}{c}{ MP } & $\mathrm{N}_{\mathrm{X}}-\mathrm{TB}$ & $\mathrm{TB}-\mathrm{N}^{*}$ & $\mathrm{~N}^{*}$-Iso \\
\hline 4Mix & $\mathbf{4}$ & $T$ & 123.8 & 106.8 & 129.2 & 163.0 \\
& $\mathrm{~A} 6_{3}$ & $\Delta H$ & 17.8 & 0.3 & 0.2 & 0.6 \\
5Mix & $\mathbf{5}$ & $T$ & 140.5 & 128.9 & 153.6 & 192.0 \\
& $\mathrm{~T} 3_{9}$ & $\Delta H$ & 28.9 & 0.1 & 0.6 & 2.1 \\
6Mix & $\mathbf{6}$ & $T$ & 98.3 & 89.0 & 116.1 & 124.1 \\
& $\mathrm{~T}_{4}$ & $\Delta H$ & 15.7 & $<0.1$ & 0.1 & 0.5 \\
7Mix & 7 & $T$ & 139.3 & 125.5 & 162.9 & 182.3 \\
& $\mathrm{O}_{7}$ & $\Delta H$ & 21.1 & 0.1 & 0.5 & 0.2
\end{tabular}

bin size is given in the (Fig. S1, ESI $\dagger$ ). Previously we have noted that a tight distribution of bend angles leads to highly stable TB phases (i.e. $T_{\mathrm{TB}-\mathrm{N}} / T_{\mathrm{N}-\mathrm{Iso}}$ tends towards 1 ), and in the present case we also find that the highest scaled $\mathrm{N}_{\mathrm{X}}$-TB transition temperature $\left(T_{\mathrm{X}-\mathrm{TB}} / T_{\mathrm{N}-\mathrm{Iso}}\right)$ also correlates with the breadth of bend angle distributions shown below.

Having demonstrated that the $\mathrm{N}_{\mathrm{X}}$ phase reported by Archbold can also be observed in using a number of different - albeit structurally similar - bimesogens. We next prepared mixtures using trimeric and tetrameric host materials that exhibit the TB phase in their neat state: $\mathrm{A6}_{3} ; \mathrm{T}_{3} 9 ;{ }^{42} \mathrm{~T}_{4} 9 ;{ }^{42,43} \mathrm{O}_{7}{ }^{44}{ }^{44}$ Other materials possibly of interest, namely $\mathrm{A6}_{4},{ }^{48} \mathrm{O6}_{7},{ }^{44}$ and $\mathrm{D} 11_{3}(2)^{29}$ are not presently available to us in sufficient quantity for the accurate creation of mixtures.

All four mixtures reported in Table 2 were all found to exhibit $\mathrm{N}^{*}$, TB and $\mathrm{N}_{\mathrm{X}}$ phases. The optical textures of each material were not significantly different from the dimeric materials, as shown in Fig. 5a. Following the transition from the TB phase into the $\mathrm{N}_{X}$ phase we observe a change in birefringence, we also note that the striations present in the rope-like texture become far more pronounced (Fig. 5b versus Fig. 5d, see also Fig. S14 in ESI $\dagger$ ). We studied mixture $\mathbf{6 M i x}$ by SAXS/WAXS, the lack of Bragg scattering confirms the nematic-like nature of the TB and $\mathrm{N}_{\mathrm{X}}$ phases. There is a small increase in the intensity of the small angle scattering peak with a function of temperature, but the $d$-spacing remains constant across the $\mathrm{N}^{*}-\mathrm{TB}-\mathrm{N}_{\mathrm{X}}$ phase range. The wide-angle scattering peak decreases in intensity slightly on entering the TB phase from the $\mathrm{N}^{*}$, shifting to slightly larger $Q\left(1.286 \AA^{-1}\right.$ to $1.314 \AA^{-1}, 4.9 \AA$ to $4.8 \AA$ respectively). The intensity of the wideangle scattering peak increases slightly on going from the TB phase to the $\mathrm{N}_{\mathrm{X}}$, but the position remains the same at $1.314 \AA^{-1}$. We do not observe any further scattering peaks from $\mathbf{6 M i x}$ to a maximum $d$-spacing of $\sim 125 \AA\left(Q=0.05 \AA^{-1}\right)$. Lastly, we note that the small associated enthalpy of the $\mathrm{N}_{\mathrm{X}}$-TB transition exhibited by $\mathbf{4 M i x}-\mathbf{7 M i x}$ is consistent with mixtures formed of dimers (Table 1), and is consistent with the transition between each phase being weakly first order (Fig. 5f) as expected of a nematic-to-nematic transition. Mixtures $\mathbf{4 M i x}-7 \mathbf{M i x}$ demonstrate that the $\mathrm{N}_{\mathrm{X}}$ phase can be formed across a wide range of length scales, from simple dimers to tetramers. Just as with the TB phase, we suspect that the $\mathrm{N}_{\mathrm{X}}$ phase could eventually be observed in higher molecular weight oligomers, as well as in polymers.
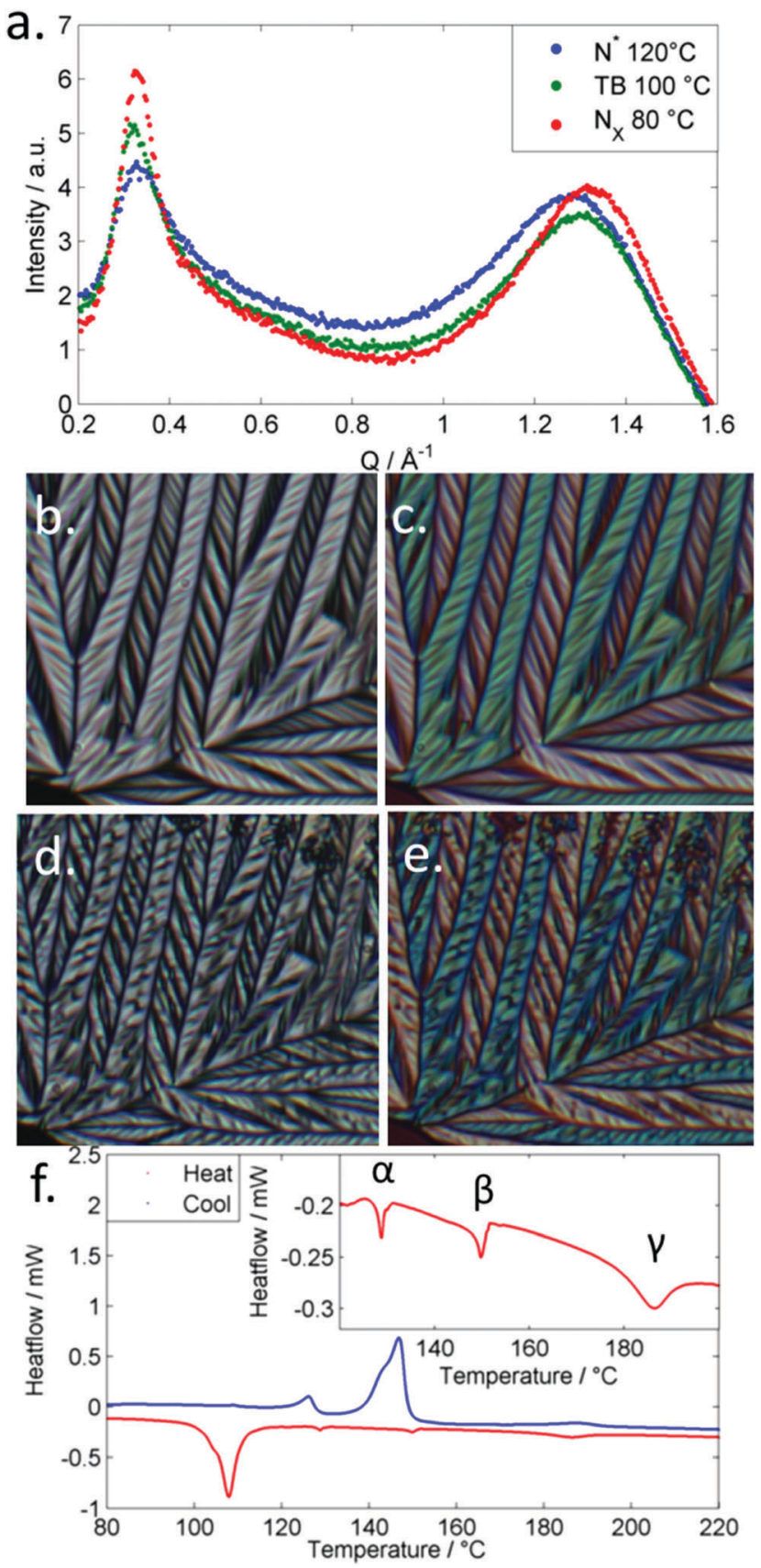

Fig. 5 (a) Plot of intensity (arb.) as a function of $Q\left(\AA^{-1}\right)$ for 6 Mix recorded in the chiral nematic, TB and $N_{X}$ phases. Photomicrographs of: (b) the rope texture of $4 \mathrm{Mix}$ in the TB phase at $115.0{ }^{\circ} \mathrm{C}$; (c) same as (b) with a $\frac{1}{4}$ waveplate inserted; (d) the rope texture of the $\mathrm{N}_{x}$ phase of $4 \mathrm{Mix}$ at $106^{\circ} \mathrm{C}$; (e) same as (b) with a $\frac{1}{4}$ waveplate inserted. All four photomicrographs are of approximately the same region of the sample in question. (f) DSC trace of mixture $5 \mathrm{Mix}$ obtained at a heat/cool rate of $10{ }^{\circ} \mathrm{C} \mathrm{min}^{-1}$, the insert is an expansion of the cooling cycle, while the annotations $-\alpha, \beta$, and $\gamma-$ refer to the $N_{X}-T B, T B-N^{*}$ and $N^{*}-$ Iso transitions respectively.

Recently we reported several chiral bimesogens which were prepared with a view to obtaining examples of this $\mathrm{N}_{\mathrm{X}}$ phase in a pure material; however none of these materials exhibited the $\mathrm{N}_{\mathrm{X}}$ phase and instead variously exhibit $\mathrm{N}^{*}, \mathrm{~TB}, \mathrm{SmA}, \mathrm{SmC}$, and SmB phases. ${ }^{7,49}$ To study the role of the chiral dopant we prepared 
Table 3 Transition temperatures $\left(T,{ }^{\circ} \mathrm{C}\right)$ associated enthalpies $\left(\Delta H, \mathrm{~kJ} \mathrm{~mol}^{-1}\right)$ for binary mixtures $\mathbf{1}$ Mix, $\mathbf{8} \mathbf{M i x}$ and $\mathbf{9 M i x}$, featuring $C B 9 C B$ as host $(90 \mathrm{wt} \%$ ) and various chiral dopants (10 wt\%). Transition temperatures and associated enthalpies were determined by DSC at $10{ }^{\circ} \mathrm{C} \mathrm{min}-1$ and are the average of two cycles

\begin{tabular}{lllllrr}
\hline No. & Chiral dopant & & MP & $\mathrm{N}_{\mathbf{X}}-\mathrm{TB}$ & $\mathrm{TB} \mathrm{N}^{*}$ & $\mathrm{~N}^{*}$-Iso \\
\hline 1Mix & \multirow{2}{*}{ RM1041 } & $T$ & 85.9 & 81.3 & 98.2 & 116.9 \\
& & $\Delta H$ & 33.4 & 0.2 & 0.7 & 1.7 \\
$\mathbf{8 M i x}$ & $\mathbf{8}$ & $T$ & 79.9 & - & 78.4 & 110.9 \\
& & $\Delta H$ & 29.9 & - & 0.3 & 1.2 \\
9Mix & \multirow{2}{*}{} & $T$ & 81.4 & - & 73.9 & 106.0 \\
& & $\Delta H$ & 31.1 & - & 0.2 & 1.3 \\
\hline
\end{tabular}

binary mixtures between $\mathrm{CB} 9 \mathrm{CB}$ and separately the two chiral dimers 8 and 9 (Fig. 5 and Table 3). Compound 8 exhibits a chiral spacer of odd parity, whereas $\mathbf{9}$ has a mesogenic unit incorporating a [2,2]-paracyclophane exhibiting planar chirality (Fig. 6).

Whereas 1Mix exhibits the $\mathrm{N}_{\mathrm{X}}$ phase we find mixtures 8Mix and 9Mix do not. We measured the HTP value of RM1041 from binary mixtures with 5CB via the Cano wedge method, giving a value of $88 \mu^{-1}$; almost two orders of magnitude larger than those of the other chiral dopants studied. ${ }^{7,49}$ This result suggests that a large value of helical twisting power is essential for the formation of the $\mathrm{N}_{\mathrm{X}}$ phase, rather than simply an optically active molecule or some other undefined parameter. While the local structure of the $\mathrm{N}_{\mathrm{X}}$ phase is presently unknown, some yet-to-be-observed one-dimensional modulated nematic structures have recently been proposed to occur in highly chiral systems, ${ }^{50}$ and this warrants further study.

The possibility that the $\mathrm{N}_{\mathrm{X}}$ phase could be a re-entrant $\mathrm{N}^{*}$ phase can be discounted as the optical textures of the $\mathrm{N}^{*}$ phase are not present in the $\mathrm{N}_{\mathrm{X}}$, instead this phase exhibits effectively the same optical textures as the TB phase (Fig. 5b-e) with slightly different birefringence. We note that the change in birefringence at the phase transition is abrupt and separate from the continual change in birefringence across the TB phase as a function of temperature - this is illustrated in the ESI $\dagger$ video to this article. The change in birefringence suggests a reorganization of molecules within the helical TB structure, and this is accompanied by a weak first order phase transition.

Given the similarity in optical textures and SAXS experiments we consider that the structure of the $\mathrm{N}_{\mathrm{X}}$ phase is structurally similar to the TB phase. As the transition occurs

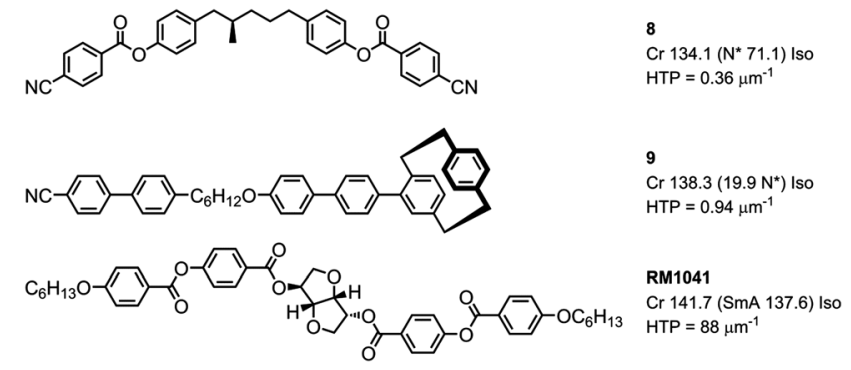

Fig. 6 Molecular structures, transition temperatures $\left(^{\circ}\right)$ and helical twisting power values $\left(\mathrm{HTP}, \mu \mathrm{m}^{-1}\right)$ for the three chiral dopants used. on cooling from the TB phase, one might expect the structure to be condensed, such that the molecules may have fewer freedoms in the $\mathrm{N}_{\mathrm{x}}$ phase over that in the TB phase. The combination of these observations indicates that the $\mathrm{N}_{\mathrm{x}}$ phase is a new variant of the TB phase, and if this is the case it demonstrates twist-bend phenomena have the potential to be polymorphic. The classical TB phase is uniaxial, and one intriguing possibility highlighted by theory is the formation of a biaxial TB phase in highly chiral systems. ${ }^{50}$ We would expect that the transition between uniaxial and biaxial TB phases would be weakly first order. Dozov and Meyer described the possibility of a phase analogous to the twistgrain boundary phase (TGB), with the smectic layers omitted in favor of the pseudo-layer structure of the TB phase, giving the twist-grain boundary twist-bend $\left(\mathrm{TGB}_{\mathrm{TB}}\right)$ phase. ${ }^{51}$ The $\mathrm{TGB}_{\mathrm{TB}}$ phase is a possibility that warrants further experimental study, although a first-order transition between a purely 'nematic' TB phase and a 'TGB' TB phase does not appear to be predicted to occur. Longa and Tomczyk recently suggested the formation of a globally polar and chiral twist-bend nematic $\left(\mathrm{N}_{\mathrm{TB}_{\mathrm{P}}}{ }^{*}\right)$ and predict that the phase sequence $\mathrm{I}-\mathrm{N}^{*}-\mathrm{TB}-\mathrm{N}_{\mathrm{TB}_{\mathrm{P}}}{ }^{*}{ }^{52}$ as well as highlighting the possibility of reentrant polymorphisms incorporating one (or more) twist-bend phases. Given the optical textures of the $\mathrm{N}_{\mathrm{X}}$ phase are quite dissimilar to those of the $\mathrm{N}^{*}$ phase we do not consider it likely to be a reentrant phase, however the possibility of a polar/chiral TB phase is an intriguing possibility that merits further study.

Based on optical textures we have no reason to believe the $\mathrm{N}_{\mathrm{X}}$ phase reported in this work is the same as the splay nematic $\left(\mathrm{N}_{\mathrm{S}}\right)$ recently described by Mertelj et al. ${ }^{53}$ - the $\mathrm{N}_{\mathrm{S}}$ phase displays the same optical textures as the classical nematic (schlieren etc.), whereas the optical textures of the $\mathrm{N}_{\mathrm{X}}$ phase are far closer to those of the 'classical' TB phase. Lastly we note that the $\mathrm{N}_{\mathrm{x}}$ phase could, more speculatively, be a completely new nematic-like phase type yet to be predicted by theory.

\section{Conclusions}

We have prepared seven binary mixtures between a high HTP chiral dopant, RM1041, and liquid crystalline dimers (CB9CB, $\mathrm{CB} 8 \mathrm{OCB}, \mathrm{CBCC6OCB})$, trimers $\left(\mathrm{A6}_{3}, \mathrm{~T}_{9}\right)$ and tetramers $\left(\mathrm{T}_{9}, \mathrm{O}_{7}\right)$. Each mixture studied exhibits chiral nematic and twist-bend modulated nematic-like phases, as well as a lower temperature nematic-like phase which we denote $\mathrm{N}_{\mathrm{X}}$. Given the similarity in optical texture (Fig. 2 and 5), small associated enthalpy values (Tables 1, 2 and Fig. 5f) and lack of Bragg scattering in SAXS/WAXS experiments (Fig. 3 and $5 \mathrm{a}$ ) we believe the $\mathrm{N}_{X}$ phase reported herein in mixtures is the same phase as reported by Archbold et al. ${ }^{40}$ As the $N_{X}$ phase can be formed seemingly irrespective of the chemical composition of the dimer/oligomer host, we studied the nature of the chiral additive. Two low HTP dopants were found not to give the $\mathrm{N}_{\mathrm{X}}$ phase, although the TB phase was retained, suggesting a strong link between the chiral strength of the dopant and the incidence of the $N_{X}$ phase. We believe the $N_{X}$ phase to be a new variant of the TB phase suggesting that twist-bend phenomena have the potential to be polymorphic. 


\section{Conflicts of interest}

There are no conflicts to declare.

\section{Acknowledgements}

The authors thank the EPSRC for funding the Bruker D8 SAXS equipment via grant EP/K039660/1 and ongoing work via EP/ M020584/1. Dr Craig Archbold is thanked for providing samples of CA23 and M10. RJM would like to thank Wojciech Tomczyk for providing a preprint copy of ref. 52 .

\section{References}

1 I. Dozov, Europhys. Lett., 2001, 56, 247-253.

2 M. Cestari, S. Diez-Berart, D. A. Dunmur, A. Ferrarini, M. R. de la Fuente, D. J. Jackson, D. O. Lopez, G. R. Luckhurst, M. A. Perez-Jubindo, R. M. Richardson, J. Salud, B. A. Timimi and H. Zimmermann, Phys. Rev. E: Stat., Nonlinear, Soft Matter Phys., 2011, 84, 031704.

3 C. Zhu, M. R. Tuchband, A. Young, M. Shuai, A. Scarbrough, D. M. Walba, J. E. Maclennan, C. Wang, A. Hexemer and N. A. Clark, Phys. Rev. Lett., 2016, 116, 147803.

4 D. Chen, J. H. Porada, J. B. Hooper, A. Klittnick, Y. Shen, M. R. Tuchband, E. Korblova, D. Bedrov, D. M. Walba, M. A. Glaser, J. E. Maclennan and N. A. Clark, Proc. Natl. Acad. Sci. U. S. A., 2013, 110, 15931-15936.

5 V. Borshch, Y. K. Kim, J. Xiang, M. Gao, A. Jakli, V. P. Panov, J. K. Vij, C. T. Imrie, M. G. Tamba, G. H. Mehl and O. D. Lavrentovich, Nat. Commun., 2013, 4, 2635.

6 E. Gorecka, N. Vaupotic, A. Zep, D. Pociecha, J. Yoshioka, J. Yamamoto and H. Takezoe, Angew. Chem., Int. Ed., 2015, 54, 10155-10159.

7 R. J. Mandle and J. Goodby, RSC Adv., 2018, 8, 18542-18548.

8 R. J. Mandle, E. J. Davis, C. T. Archbold, S. J. Cowling and J. W. Goodby, J. Mater. Chem. C, 2014, 2, 556-566.

9 W. D. Stevenson, Z. Ahmed, X. B. Zeng, C. Welch, G. Ungar and G. H. Mehl, Phys. Chem. Chem. Phys., 2017, 19, 13449-13454.

10 B. Robles-Hernandez, N. Sebastian, M. R. de la Fuente, D. O. Lopez, S. Diez-Berart, J. Salud, M. B. Ros, D. A. Dunmur, G. R. Luckhurst and B. A. Timimi, Phys. Rev. E: Stat., Nonlinear, Soft Matter Phys., 2015, 92, 062505.

11 J. W. Emsley, P. Lesot, G. R. Luckhurst, A. Meddour and D. Merlet, Phys. Rev. E: Stat., Nonlinear, Soft Matter Phys., 2013, 87, 040501.

12 J. W. Emsley, M. Lelli, A. Lesage and G. R. Luckhurst, J. Phys. Chem. B, 2013, 117, 6547-6557.

13 J. P. Jokisaari, G. R. Luckhurst, B. A. Timimi, J. F. Zhu and H. Zimmermann, Liq. Cryst., 2015, 42, 708-721.

14 Z. P. Zhang, V. P. Panov, M. Nagaraj, R. J. Mandle, J. W. Goodby, G. R. Luckhurst, J. C. Jones and H. F. Gleeson, J. Mater. Chem. C, 2015, 3, 10007-10016.

15 C. Meyer, C. Blanc, G. R. Luckhurst and I. Dozov, presented in part at the The 13th European Conference on Liquid Crystals, Manchester, UK, 2015-09-07, 2015.
16 P. K. Challa, V. Borshch, O. Parri, C. T. Imrie, S. N. Sprunt, J. T. Gleeson, O. D. Lavrentovich and A. Jakli, Phys. Rev. E: Stat., Nonlinear, Soft Matter Phys., 2014, 89, 060501.

17 R. J. Mandle, Soft Matter, 2016, 12, 7883-7901.

18 R. J. Mandle and J. W. Goodby, Chem. - Eur. J., 2016, 22, 18456-18464.

19 E. E. Pocock, R. J. Mandle and J. W. Goodby, Soft Matter, 2018, 14, 2508-2514.

20 A. Lesac, U. Baumeister, I. Dokli, Z. Hameršak, T. Ivšić, D. Kontrec, M. Viskić, A. Knežević and R. J. Mandle, Liq. Cryst., 2018, 1-10, DOI: 10.1080/02678292.2018.1453556.

21 R. J. Mandle, C. T. Archbold, J. P. Sarju, J. L. Andrews and J. W. Goodby, Sci. Rep., 2016, 6, 36682.

22 C. T. Archbold, R. J. Mandle, J. L. Andrews, S. J. Cowling and J. W. Goodby, Liq. Cryst., 2017, 44, 2079-2088.

23 C. Greco, G. R. Luckhurst and A. Ferrarini, Soft Matter, 2014, 10, 9318-9323.

24 N. Vaupotic, M. Cepic, M. A. Osipov and E. Gorecka, Phys. Rev. E: Stat., Nonlinear, Soft Matter Phys., 2014, 89, 022506.

25 A. Zep, S. Aya, K. Aihara, K. Ema, D. Pociecha, K. Madrak, P. Bernatowicz, H. Takezoe and E. Gorecka, J. Mater. Chem. C, 2013, 1, 46-49.

26 Y. Wang, G. Singh, D. M. Agra-Kooijman, M. Gao, H. K. Bisoyi, C. M. Xue, M. R. Fisch, S. Kumar and Q. Li, CrystEngComm, 2015, 17, 2778-2782.

27 A. Al-Janabi, R. J. Mandle and J. Goodby, $R S C A d v .$, 2017, 7, 47235-47242.

28 M. R. Tuchband, D. A. Paterson, M. Salamończyk, V. A. Norman, A. Scarbrough, E. Garcia, C. Wang, J. M. D. Storey, D. M. Walba, S. Sprunt, A. Jákli, C. Zhu, C. T. Imrie and N. A. Clark, 2017, arXiv:1710.00922.

29 R. J. Mandle and J. W. Goodby, Angew. Chem., Int. Ed., 2018, 57, 7096-7100.

30 G. Ungar, V. Percec and M. Zuber, Macromolecules, 1992, 25, 75-80.

31 W. D. Stevenson, J. An, X. Zeng, M. Xue, H.-x. Zou, Y. Liu and G. Ungar, Soft Matter, 2018, 14, 3003-3011.

32 E. Barry, Z. Hensel, Z. Dogic, M. Shribak and R. Oldenbourg, Phys. Rev. Lett., 2006, 96, 18305.

33 T. Ivšić, U. Baumeister, I. Dokli, A. Mikleušević and A. Lesac, Liq. Cryst., 2017, 44, 93-105.

34 R. J. Mandle, E. J. Davis, S. A. Lobato, C. C. Vol, S. J. Cowling and J. W. Goodby, Phys. Chem. Chem. Phys., 2014, 16, 6907-6915.

35 R. J. Mandle and J. W. Goodby, Soft Matter, 2016, 12, 1436-1443.

36 R. J. Mandle and J. W. Goodby, CrystEngComm, 2016, 18, 8794-8802.

37 R. J. Mandle, S. J. Cowling and J. W. Goodby, Sci. Rep., 2017, 7, 13323.

38 M. Sepelj, A. Lesac, U. Baumeister, S. Diele, H. L. Nguyen and D. W. Bruce, J. Mater. Chem., 2007, 17, 1154-1165.

39 D. Chen, M. Nakata, R. Shao, M. R. Tuchband, M. Shuai, U. Baumeister, W. Weissflog, D. M. Walba, M. A. Glaser, J. E. Maclennan and N. A. Clark, Phys. Rev. E: Stat., Nonlinear, Soft Matter Phys., 2014, 89, 022506. 
40 C. T. Archbold, E. J. Davis, R. J. Mandle, S. J. Cowling and J. W. Goodby, Soft Matter, 2015, 11, 7547-7557.

41 R. J. Mandle, C. T. Archbold, J. P. Sarju, J. L. Andrews and J. W. Goodby, Sci. Rep., 2016, 6, 36682.

42 R. J. Mandle and J. W. Goodby, RSC Adv., 2016, 6, 34885-34893.

43 R. J. Mandle and J. W. Goodby, ChemPhysChem, 2016, 17, 967-970.

44 F. P. Simpson, R. J. Mandle, J. N. Moore and J. W. Goodby, J. Mater. Chem. C, 2017, 5, 5102-5110.

45 M. J. Frisch, G. W. Trucks, H. B. Schlegel, G. E. Scuseria, M. A. Robb, J. R. Cheeseman, G. Scalmani, V. Barone, B. Mennucci, G. A. Petersson, H. Nakatsuji, M. Caricato, X. Li, H. P. Hratchian, A. F. Izmaylov, J. Bloino, G. Zheng, J. L. Sonnenberg, M. Hada, M. Ehara, K. Toyota, R. Fukuda, J. Hasegawa, M. Ishida, T. Nakajima, Y. Honda, O. Kitao, H. Nakai, T. Vreven, J. A. Montgomery Jr., J. E. Peralta, F. Ogliaro, M. J. Bearpark, J. Heyd, E. N. Brothers, K. N. Kudin, V. N. Staroverov, R. Kobayashi, J. Normand, K. Raghavachari, A. P. Rendell, J. C. Burant, S. S. Iyengar, J. Tomasi, M. Cossi, N. Rega, N. J. Millam, M. Klene, J. E. Knox, J. B. Cross, V. Bakken, C. Adamo, J. Jaramillo,
R. Gomperts, R. E. Stratmann, O. Yazyev, A. J. Austin, R. Cammi, C. Pomelli, J. W. Ochterski, R. L. Martin, K. Morokuma, V. G. Zakrzewski, G. A. Voth, P. Salvador, J. J. Dannenberg, S. Dapprich, A. D. Daniels, Ö. Farkas, J. B. Foresman, J. V. Ortiz, J. Cioslowski and D. J. Fox, Gaussian 09, 2009.

46 M. Tarini, P. Cignoni and C. Montani, IEEE Trans. Vis. Comput. Graph., 2006, 12, 1237-1244.

47 M. Salamonczyk, N. Vaupotic, D. Pociecha, C. Wang, C. H. Zhu and E. Gorecka, Soft Matter, 2017, 13, 6694-6699.

48 R. J. Mandle, Chem. Rec., 2018, DOI: 10.1002/tcr.201800010.

49 R. J. Mandle and J. W. Goodby, Liq. Cryst., 2018, 1-7, DOI: 10.1002/tcr.201800010.

50 L. Longa and G. Pajak, Phys. Rev. E: Stat., Nonlinear, Soft Matter Phys., 2016, 93, 040701(R).

51 I. Dozov and C. Meyer, Liq. Cryst., 2017, 44, 4-23.

52 L. Longa and W. Tomczyk, Liq. Cryst., 2018, DOI: 10.1080/ 02678292.2018.1499148.

53 A. Mertelj, L. Cmok, N. Sebastian, R. J. Mandle, R. R. Parker, A. C. Whitwood, J. W. Goodby and M. Copic, 2018, arXiv:1806.09964 [cond-mat.soft]. 